University of Nebraska - Lincoln

DigitalCommons@University of Nebraska - Lincoln

Faculty Publications, UNL Libraries

Libraries at University of Nebraska-Lincoln

May 2003

\title{
A model for strategic business instruction
}

Signe Swanson

University of Nebraska - Lincoln, sboudreau3@unl.edu

Tracy Bicknell-Holmes

University of Nebraska-Lincoln, tbicknel@gmail.com

Follow this and additional works at: https://digitalcommons.unl.edu/libraryscience

Part of the Library and Information Science Commons

Swanson, Signe and Bicknell-Holmes, Tracy, "A model for strategic business instruction" (2003). Faculty Publications, UNL Libraries. 161.

https://digitalcommons.unl.edu/libraryscience/161

This Article is brought to you for free and open access by the Libraries at University of Nebraska-Lincoln at DigitalCommons@University of Nebraska - Lincoln. It has been accepted for inclusion in Faculty Publications, UNL Libraries by an authorized administrator of DigitalCommons@University of Nebraska - Lincoln. 


\title{
A model for strategic business instruction
}

\author{
Signe Boudreau* and Tracy Bicknell-Holmes \\ University. Libraries, University. of Nebraska-Lincoln, N219 Love Library, \\ Lincoln, NE 68588-4100, USA
}

Available online 14 May 2004

\begin{abstract}
Collaboration among business faculty, compositton faculty; and librarians at the University of Nebraska-Lincoln has resulted in an innovative instructional model that integrates library research, writing, presentation, and team building within the context of "learning business." The model combines the expertise of faculty members and utilizes active learning principles to improve skill development in research, communication, and teamwork. This article focuses on the model's evolution and three key features-recitations, collaboration, and reframed assignments-that other institutions may adapt.
\end{abstract}

(c) 2004 Elsevier Inc. All rights reserved.

\section{Introduction}

Effective writing and presentation skills are diminished if used to share flawed or incomplete information. Likewise, excellent research skills are invalidated if the gathered information is not communicated articulately and persuasively. The complementary nature of the research and communication processes makes for an ideal instructional partnership that reinforces development of both types of skills. Further integrating the instruction into specific courses provides context for the skills and allows students to directly apply the skills in a way that makes sense to them.

Collaboration among business faculty; composition faculty; and librarians at the University; of Nebraska-Lincoln (UNL) has resulted in an innovative instructional model that integrates

* Corresponding author.

E-mail addresses: sboudreau3@unlnotes.unl.edu_ (S. Boudreau), tbicknell-tholmes I@unl.edu (T. Bicknell-Holmes). 
library research, writing, presentation, and team building within the context of "learning business." The model combines the expertise of faculty members and utilizes active learning principles to improve skill development in identified areas. This article will focus on the model's evolution and three of its most significant features. In addition, we will recommend how these features might be adapted for use at other institutions.

\section{Literature review}

The "complex nature of both business information and the academic study of business provide a need for sophisticated information handling skills and familiarity. with a wide range of sources" (Hanson, 1985, p. 187). This complexity, impacts business instruction, and a literature review reveals a variety of approaches to meeting this challenge. Business instruction ranges from a one-shot demonstration and discussion about selecting and effectively searching business databases (Cohen, 1995) to a required one-credit course covering commonly used business sources and showing basic research in business-related indexes (Kendrick, 1985). Rather than offering a scattershot selection of core sources, a common approach to business instruction is to focus on "searching for company information as the vehicle for developing search strategies and identifying specific resources" (Mai \& Nixon, 1997, p. 40). Huett, Sims, and Villalon (1997) and Ternburg (1985) also employ the company research format for instruction.

Hanson (1985) also stresses the importance of instilling transferable skills in business students since the likelihood of teaching use of all relevant business sources is small. An effective approach is to focus on concepts rather than sources. O'Keeffe (1998) describes helping students to construct a conceptual framework by demonstrating the content and interrelatedness of specific core business sources in a systematic way. Diamond and McGee (1995) emphasize concepts by focusing on the data's originators and gatherers and the contents and uses of different types of sources. In integrating a library research competency unit into a marketing course, Jacobson (1987) emphasizes broader information-related concepts over marketing-related concepts. This ensures that students not only learn skills but also understand the process and purpose of research within the context of marketing.

For the purposes of this article, however, we reviewed the literature with regard to the degree of collaboration between librarians and other faculty: Much of the collaboration found was low level.. For example, Ternburg (1985) and Cohen (1995) describe librarians and instructors working together to design demonstration sessions for electronic resources that were subsequently presented by librarians. A higher degree of collaboration is seen in a project utilizing an experimental conceptual framework for teaching business and career sources. Business writing instructors collaborated with librarians on identifying the concepts and sources to be included, but related assignments were developed and graded without librarian input (Diamond \& McGee, 1995). Another example of collaboration is a librarian and a marketing instructor developing an instruction session to support a research paper assignment.. The librarian also was responsible for grading two sections of the final paper, noting the use or lack of appropriate sources (Jacobson, 1987). 
Case study courses provide an opportunity, for greater collaboration. Crawford and Barrett (1997) discuss their "strategic alliance" in preparing students to conduct research-intensive environmental scans for a case study. Their collaboration occurs mostly behind the scenes, with an eye toward keeping the librarian apprised of upcoming case studies in order to ensure proper coverage of the topic in the library's collection. The librarian provided the one-shot instruction session and handout but was not involved in developing or grading assignments.

Team teaching is the next step in the collaboration hierarchy. A good example is Moylan's (1997) overview of collaborative instruction between a librarian and a business instructor for an international business course. The one-time instruction was designed to prepare students for a complex marketing project by introducing them to key sources. The two instructors coauthored a pathfinder and team-taught the class. Although not officially involved in grading, the librarian was able to view the bibliographies from the final project.. Another example of team teaching is Henninger and Hurlbert's (1996) work in preparing and presenting a workshop on critical thinking and research techniques within the business curriculum. The collaborators also devised an assignment specific to the workshop that is graded in part by both the instructor and the librarian.

The highest degree of collaboration and the instruction most related to our model is Judd and Tims' (1996) "interactive team teaching." This term describes two instructors from different disciplines working together in the classroom, interacting with each other and students. They detail a series of workshops on secondary marketing resources developed and delivered by a librarian and a marketing professor. Each workshop is tied to a specific course and some have associated projects. The workshops are infonnal and use scenarios to teach students how to gather and interpret data from various sources.

\section{History of the collaboration}

The basis of our model is the collaboration of librarians, business faculty, and composition faculty. As previously noted, partnering with business faculty is not new for librarians. Librarians have also historically worked with general composition faculty to provide instruction (Christensen, 1994; Gavin, 1994; Huerta \& McMillan, 2000; Hurlbert \& Weida, 1991; Isbell \& Broaddus, 1995). What makes our collaboration innovative is the combined interaction of all three groups in planning for and providing classroom instruction.

The business faculty are from the UNL College of Business Administration's (CBA) accounting, economics, and marketing departments. The librarians are the UNL University, Libraries' three business librarians. The composition faculty work in the EJ. Faulkner Writing Lab (FWL).

The FWL was established within the CBA in 1993, at a time when the business faculty thought that students were not able to write well using the language of business or to present business information persuasively. Concerns were also being raised nationally that business school graduates possessed solid mathematical skills but relatively poor oral and written communication skills. The Business-Higher Education Forum (1997) reported that corporate leaders found recent business graduates deficient in several areas including communication 
skills, teamwork, and flexibility. The gift and grant-funded FWL, developed and staffed by instructors with doctorates in English, was charged with addressing these issues.

Although UNL librarians have faculty status, for the purpose of clarity in this article, "faculty" refers to FWL and business faculty and "instructors" refers to FWL faculty, business faculty, and the librarians.

\section{Early collaboration}

At first, CBA professors simply encouraged students to seek assistance from the writing lab and the library on a drop-in basis. Gradually, the FWL assumed a more integrated role via a writing lab requirement for a variety of core business courses. Commonly referred to as recitation sections, these weekly meetings were similar in purpose to science course labs. The FWL faculty also began assisting in designing assignments for the recitations. In addition to giving students an opportunity, to interact with the FWL faculty, the recitations provided regularly scheduled time to work on assignments, most of which used small groups. The structure of the recitations incorporated several features of the team learning instructional approach including all-tenn teams, active learning, immediate feedback, and minimal lecturing (Roebuck, 1998).

As the FWL's efforts improved students' writing and presentations, business faculty became more aware of the poor quality of the information sources used for assignments. Since the business faculty recognized librarians as research and information retrieval experts, the business librarians were invited to join in working with recitation sections for several classes beginning in 1995 .

Initial collaboration among the three groups was fairly basic. Aside from the vague goal of "improving student research," no student learning outcomes were established. A librarian typically attended a recitation section only once, usually early in the semester. The librarian's presentation was formal, focusing on research mechanics and how to search specific databases. Students had little or no hands-on activity during the presentation but received a detailed, annotated resource list. Although the librarian encouraged students to contact her/ him outside of class with future questions, few students took advantage of the opportunity. This infrequent contact was the only way the librarian could identify, what students were doing in their research and any difficulties they encountered.

In spring 1998, after six semesters of collaborating, observing, and interacting with students in and outside of class and tweaking traditional methods of instruction, the FWL faculty suggested that the instructors begin planning for fall 1998 classes. In the discussions, all the instructors expressed frustration with the distinct pattern of unproductive student research behaviors they were observing:

- In terms of library resources, students used only the electronic full-text resources listed on the handout, ignoring valuable paper resources.

- Students' research topics varied enough that a single annotated resource list did not adequately cover the myriad of potential resources. 
- Students viewed the research process as a one-time-only activity to be completed at the outset of a project.

- Students could figure out a database's search mechanics but could not identify the database most appropriate for their topics.

- The long resource list encouraged students to rely more on what was supplied to them and to do less of their own exploring.

In addition, lacking direct access to student work, librarians often made accidental discoveries about the information students retrieved and how they used it. For example, the librarians worked with students in a marketing class on research to create a profile of a particular target consumer. At the next stage of the project, students sought information to support the creation of print advertisements aimed at the target consumer. Through talking to the students, the librarians discovered that much of the needed information was already present in their consumer profiles, but students failed to interpret and apply that information to the advertisement.. This problem would likely have gone unnoticed if students had not voluntarily shared their target consumer profiles with the librarians.

Conversations with the FWL and business faculty about the finished student products identified additional problematic student outcomes:

- Students typically based projects on personal assumptions rather than on valid and reliable data or information.

- Students did not critically evaluate infOlmation sources and used inappropriate Internet resources.

- Sources were not cited or were cited improperly.

\section{The beginning and evolution of the model}

From these observations, the instructors concluded that their instruction was not having the intended effect on students' conceptions of research and their resulting behaviors. However, the idea of integrated instruction in writing, presentation, and research skills still seemed to hold promise. Rather than completely abandon the model, the instructors resolved to expand it by involving more extensive instructor interaction.

The instructors quickly determined that clearly articulating student learning outcomes was necessary before further development of the model could occur: They began by creating a behavioral definition of research that identified an "able researcher" as being able to:

- understand that research is recursive and should be conducted at every point of a project where information is lacking;

- distinguish between free Internet resources and the library's electronic subscription resources;

- gather all resources necessary to complete a project, regardless of format;

- critically evaluate all information retrieved; 
- recognize the necessity. of citing information and properly cite resources; and

- emulate teamwork as modeled by the recitation instructors, who use individual expertise to advantage.

Using these learning outcomes as a basis, the model was adjusted to its current structure. The recitations were retained, as was collaboration among the three instructor groups. However, in the current instructional model, the librarians' participation was no longer limited to presentations on library resources. Instead, the librarians are involved in the recitations from development to delivery, a process that often begins 6 months to a year in advance of a course's start.

The planning meetings are informal, with a loose agenda usually focused on a central topic. Early planning focuses on identifying student learning outcomes, and later planning centers on how to structure assignments. Planning continues throughout the duration of a course, and these meetings often focus on teaching techniques that need adjustment, the effectiveness of current assignments, or problems identified in a recitation. In addition, informal collaboration occurs spontaneously during recitation sessions when student activities spark an idea or a new frustration. Each of the collaborators brings issues to the fore and proposes ideas on assignments and instruction for brainstorming. Throughout the planning process, input from each instructor is not only encouraged but also expected, and the diverse opinions expressed enhance creative problem solving and idea generation.

The librarians work with business and FWL faculty, to design assignments that reinforce course content and focus research topics so that instruction can be effectively targeted to specific types of resources and search techniques. While FWL faculty. ensure that assignments ask students to demonstrate specific communication skills essential for "real life" business situations, librarians ensure the assignments require demonstration of proficiency in retrieving and evaluating different information types and can be completed using resources reasonably accessible by students. Business faculty ensure that the assignments necessitate application of the important concepts covered in class lectures and reading materials. As a part of this process, existing assignments of a more traditional nature have been "reframed" to increase their relevance and make them more applicable to situations or problems that could be encountered in future jobs. The instructors also work together to identify instruction techniques appropriate for each assignment. .

Recitations are structured so that students spend most of their time working on assignments in a workshop context and interacting with their small groups and the instructors. To encourage students to see the research process as recursive, utilize information in all formats, and evaluate the information they find, the librarians now have a greater in-class presence. Depending on the course and type of assignment, a librarian may attend a recitation several times during a semester or every week. In this context, the FWL faculty and librarians provide fluid instruction on research, writing, and presentation topics related to an assignment, while the business faculty member is available to answer questions specific to class content.

The nature of the recitations is such that most in-class instruction is informal and customized to the students' current needs and is offered to individuals or small groups as questions are raised. The instructors rove from one group to the next, observing their work and supplying suggestions, questions, or answers. Brief impromptu. lectures are also made if the instructors 
notice a recurring problem among groups. The librarians' formal presentations are timed to correspond with strategic points in an assignment. These presentations are brief, focusing on resources or search strategies relevant to a particular aspect of the assignment and heavily emphasizing the importance of evaluation and critical thinking. The librarian typically leads a related hands-on exercise, such as comparing and contrasting a "good". and "bad" Web site in order to foster evaluation skills. Resource handouts are minimal and focus on things such as article indexes with which students must work in order to find information themselves.

The instructors' collaboration models the teamwork skills that CBA students are expected to develop in order to function effectively in future careers. In the recitation sections, students have a valuable opportunity, to collaborate not only with each other but also with experts in the subject matter, in communication, and in research. The various interactions exhibited produce a fluid definition of "team" in which the instructors and other students become extended members of a small group.

Grading varies based on the business faculty' involved and the course. Usually, the FWL faculty are responsible for monitoring the students' work and assigning grades for the recitations. However, the business faculty' and librarians review assignment drafts throughout the semester as well as the final products to assess student learning outcomes, identify problem patterns, and adjust instruction plans accordingly. Although the librarians usually do not have direct input in grading, they feel free to point out areas where student products could be improved. In addition, the collaborative nature of the instruction ensures that the FWL faculty have come to understand the types of sources that point to evidence of student learning outcomes.

\section{Successful parts of the model}

After several years of regular observations of and interactions with students, reviews of student products, and reviews of the questions received by the instructors, three features of our instruction method stand out as having the most noticeable impact on student outcomes: collaboration, recitations, and reframed assignments.

\subsection{Collaboration}

Collaboration combines the efforts, knowledge, experience, and perspectives of the librarians and business and FWL faculty' to great effect in designing assignments, crafting teaching techniques, and modeling teamwork behavior. Considering a proposal or recommendation from multiple perspectives often illuminates hidden benefits and detriments, strengthens the overall planning process, and greatly improves the ideas originally produced in isolation.

Collaboration has been especially successful in improving assignments. An industry research project provides an example. In an economics class, students were allowed to choose their own industry, for a research project.. Often students chose small, very specialized product lines or industries dominated by private companies that were difficult to research, making a complex project more difficult and frustrating. The librarians suggested that limiting 
the choice to a list of industries where research would result in success would ease frustrations and focus students on evaluating and interpreting information. The librarians worked with the economics faculty member to develop a select list of industries. Not only did the student products improve, but interactions with students in class and observations of their work also illustrated a more positive research experience.

Review of student work by librarians is another aspect of collaboration that has proven useful.. Regularly attending recitation sections provides the librarians with a better perspective on how students conduct research but offers little insight into how students apply information. In addition, the librarians sometimes identify patterns of research behavior or information use in student projects that the other faculty may not. Periodic review and assessment of drafts and final projects reveal much about students' understanding of the research process and how they use information (Christensen, 1994). As a result: of having direct access to student work, librarians have improved instructional responsiveness by addressing problems resulting from gaps in instruction or understanding of student behavior.

Aside from improved instruction and assignments, business students benefit in more subtle ways from the collaboration. CBA places a high degree of emphasis on group work throughout the curriculum in order to "enable students to understand group dynamics, to work effectively as group members, to build cooperative effort with the team one leads, and to organize and delegate tasks" (College of Business Administration, 2002, paragraph 3). Schaible and Robinson (1995) have shown that when teachers model the collaborative behaviors and values they want their students to exhibit, students are positively affected. Throughout the years, the instructors have noticed that students with previous experience in writing lab recitations begin projects more quickly and work more smoothly as a team than student groups who have not experienced these interactive recitations.

\subsection{Recitations}

The most rewarding aspect of our model is the customized, just-in-time instruction provided in the recitations. By teaching students as needed, i.e., just-in-time, the instructors hope to overcome the "forgetting curve" by enabling students to "move efficiently from theory to application and understand both better" (Hudspeth, 1992, p. 8).

The recitations provide a rare opportunity, for librarians to directly observe and interact with students as they are doing research, thereby allowing a more proactive approach to instructional problem solving and a better understanding of the difficulties the students face. Through observation and interactions with students during recitations and regular review of student products, we have discovered that the absence of questions does not necessarily mean that students know what they are doing. For example, the Statistical Universe database is a valuable resource for market research, but students who used it often told the librarians that they could not find any information on a topic. When questioned, students seemed to understand how to search Statistical Universe and seemed to be using good search terms. In working with a small group on Statistical Universe during a recitation, the librarian realized that she judged certain resources in the results list as valuable because she knew from experience that they often contained good data. The students, however, saw nothing useful in 
the results list and did not explore further to see why they had retrieved the results. This interaction explained numerous frustrating experiences and changed the way students are now introduced to Statistical Universe. Their presence in the recitations enables the librarians to witness and address problems as they occur and thwart emerging patterns of unproductive research behavior immediately.

Just-in-time instruction is paired with active learning, which research has indicated helps students to "learn effectively, apply knowledge, develop independent learning skills, and prepare for their future careers" (Sivan, Leung, Woon, \& Kember, 2000, p. 387). From their own experiences, the instructors have also seen that students learn by doing and teach one another. In the beginning, we thought each student needed to do the work individually to learn from the experience. Over the years, we have discovered that students learn from seeing other students perform searches, questioning each other about results and techniques, and sharing knowledge. Students who have seen a search technique perfonned by another student are likely to try it again themselves in another situation. Allowing students to shape their learning experience by working through assignments collaboratively in the presence of experts has shifted the instructor's role from lecturer to that of a facilitator who mediates, advises, and challenges (Roebuck, 1998).

The recursive nature of the composition process emphasized in the recitations reinforces the concept of library research as a "series of recurring activities that include searching, retrieving, reading or skimming material to evaluate its applicability; summarizing relevant material, and analyzing retrieved information for adequacy and sufficiency" (Mellon, 1984, p. 477). FWL faculty emphasize the expectation that students will analyze and rework projects throughout the semester and remind students that valid resources must be used for answers or to support claims. The recitation session format also reinforces the image of librarians as a resource. If students do not already have the necessary information, additional research must be done, and students are encouraged to consult the librarians for assistance or guidance. Overall, the librarians have noticed an increased number of students coming to the library to seek help, better preparation on the part of students when they seek help outside the recitations, and more advanced and complex questions from students than occurred early on in the history of the collaborative model.

\subsection{Reframing assignments}

The third significant feature of our collaboration was a discovery that immediately revitalized classroom activities. Reframing assignments has been a powerful tool for increasing the relevance of projects for students and affecting student outcomes. In particular, making assignments more realistic and changing the audience for student writing and presentation has impacted the overall quality of student projects. Here are some examples of how assignments were reframed:

- In an economics class, students traditionally wrote a research paper on an international economics topic. The project was revised so that students prepared a manuscript to be submitted for publication consideration in an undergraduate research journal.. The 
students' audience for the paper was changed to a group of their peers. The students were also required to research various undergraduate journals and their manuscript requirements and to read articles published in the journals to get an idea of appropriate writing style.

- For a combined business-computer science-engineering honors class, a project on Fourier Analysis was changed from a traditional research paper into an oral presentation given to a panel of "experts" who judged the groups on their content and presentation skills. The panel members were recruited from the campus community, and included mathematics, computer science, and business faculty, the associate dean of CBA, the director of the honors program, and an associate vice chancellor for the university.

- For a marketing class, students traditionally wrote a paper about a product that included a discussion of market, product, and target consumer group. When the assignment was reframed, teams of students assumed the identities of marketers for a shoe company and developed a company name to identify their group. The students then compiled a target consumer profile using secondary research sources and developed a shoe for that target consumer. Finally, they created print and Web page advertisements targeted at that consumer. In creating advertisements, students were asked to justify, every choice (e.g., color, font, graphics, etc.) in terms of the consumer profile and the underlying research.

In each case, the audience for the students' project or paper was shifted. Students were no longer simply working to give the professor what they believed he/she wanted in return for a grade. Instead, students were writing or presenting persuasively to reach a particular audience. A thorough review of student products before and after reframing the assignments indicates that this technique has had immediate positive results. In the case of the economics assignment, the evidence of student learning displayed in the writing improved markedly and the sources cited were of higher quality. Students' writing more strongly reflected an understanding of economics principles and demonstrated an increased proficiency in writing in the language of economics. Conversations with students before and after the reframing indicated more positive student interest in the reframed project and a better understanding of the necessity of writing to a particular audience. After several years of polishing this assignment and encouraging students to write with the goal of journal publication, two out of four group papers were accepted for publication in the same semester (Bogardi, Knudsen, \& Schildt, 2001).

Evaluation of student products before and after reframing in other classes revealed higher quality resources used by students. For instance, prior to reframing the marketing assignment, target consumer profiles were typically brief paragraphs based primarily on assumptions, guesses, and cursory Internet forays. Sources of information were rarely evaluated and frequently were not cited. With the reframed assignment, target profiles were consistently several pages long and replete with facts gleaned from library and Internet resources of repute. Sources were more consistently cited as well. 
Student interest in and the perceived relevance of the assignments to their future work lives has increased as well.. For example, in a conversation with students about the difficulty of researching a target consumer, the instructors pointed out that graduates with a degree in marketing are paid large salaries to do this type of research and apply it to the development of advertisements seen every day. In subsequent conversations with these students, theiri interest in the project seemed revitalized. Student evaluations have regularly noted that the assignments and the work accomplished in the recitations were the most valuable part of their studies in CBA.

\section{Meeting student learning outcomes}

In the spring of $200 \mathrm{I}$, the business librarians were awarded a small grant to study the collaborative model and work to measure its teaching success. Initial planning took place over the summer. The bulk of the study took place during fall 2001 with adjustments during spring 2002. Marketing 341, a class required by all business students receiving a degree from the CBA, was chosen as the basis for the study. Although the majority of the data have not yet been tabulated, preliminary data resulting from the pretest, interviews with small student groups, in-class observations, and review of student assignments have proven useful in identifying where instruction outcomes are being met.

In particular, student group activities demonstrated that students were conducting research recursively and working to gather information at each stage as questions were raised or assumptions were made. They were questioning the information they found and distinguishing between free Internet sources and the quality resources found via the library and its Web site. Quality, sources were being chosen and cited, although sometimes incompletely. Student interactions in class demonstrated teamwork, sharing workloads, and expertise to cooperatively complete the project, as well as project management skills.

\section{Limitations of the model}

As with many innovations, however, the model has some limitations. The high goals we set for providing flexible, just-in-time instruction, relevant assignments, and facultystudent interaction have required a large time commitment, both in and out of the classroom.

Each semester, the instructors review existing instructional plans and modify, them based on the successes and failures of the previous semester. A single plan does not lend itself to every business course, so a new plan is developed whenever a course instru,ctor first implements the model.. These activities translate into numerous planning meetings.

Meetings continue to be a necessity even after a course begins. Although much of the work occurs in the preimplementation stage, the emphasis on responsiveness in the recitations 
requires a high degree of flexibility and adaptability. While this responsiveness benefits students by immediately addressing questions or concerns that have arisen, it creates extra work as the instructors must quickly revise plans.

Depending on class size, the number of recitation sections, and the frequency with which they meet, the in-class time commitment can be equally demanding.. For example, a marketing class required of all majors in CBA often has as many as 15-20 recitation sections each semester. Even with three librarians to cover the workload, a fairly large amount of time is spent in class, especially if the librarians visit the recitations numerous times during the semester.

The collaborators include a core group consisting of three librarians and two FWL faculty, plus a revolving group of business faculty and graduate teaching assistants. Aside from the difficulty of scheduling meetings for so many people, there are the occasional problems with negotiating diverse opinions during discussion. In terms of implementation, different teaching styles, personalities, and interpretations may produce varying results among recitations sections for the same course. Lastly, the group has never designated a "leader," and prioritization, focus, and purpose sometimes suffer as a result..

\section{Adaptability of the model}

The characteristics that make this collaborative instruction innovative also make it less transferable to other environments. Institutions without an established writing center like the FWL may find it impossible to replicate the model exactly. However, almost any institution can adapt the model's three key features: recitations, collaboration, and reframed assignments.

Library resources compete with the Internet for students' attention (Lubans, 1999; Morrison, Kim, \& Kid, 1998), and making library research skills relevant for students is a struggle. Working with teaching faculty to reframe existing assignments is a simple but powerful tool for increasing research's relevance and utility. When developing "real-world" assignments, keep in mind common workplace concerns: audience, collaboration, budget and time constraints, visually informative texts, and problem solving (Fennick et al., 1993). For example, ask students to research a company's competitor and write a persuasive memo to the company president presenting facts about the competitor's threat to the company's success and recommending responsive action. Have students conducting industry research use their gathered information to present oral arguments for or against a proposed congressional bill. Divide students studying collective bargaining into union and management teams and have them research and negotiate a portion of a labor contract..

At the heart of the model lies a strong belief that writing and research "should be viewed as a continuum, and that they are inseparable and weave continuously into each other" (Isbell \& Broaddus, 1995, p. 61). Collaboration with writing and/or communication specialists is another feature of the model that could be successfully adapted. The presence of a formal writing center, however, is not a prerequisite for integrating instruction in research, writing, and presenting. Instead, potential collaborators could be identified from among faculty and graduate students in the English composition or vocational education departments. Business 
communication specialists might also be recruited externally in the form of practitioners, such as local company executives.

One significant feature of our instruction is faculty with different areas of expertise working together with students in weekly scheduled recitations. This aspect of the model can also be adapted, albeit with modifications. Librarians could easily work cooperatively with communication specialists and teaching faculty in more informal "workshop" settings. For example, time for students to work on assignments could be scheduled into regular class meetings. Another option might be to require each small group to arrange several working meetings outside of class with all of the collaborating instructors.

\section{Conclusion}

Our instructional model integrates library research, wntmg, and presentation and team building skills within the context of "learning business," thereby taking advantage of the complementary nature of the research and communications processes. By capitalizing on this ideal instructional partnership, the model reinforces students' development of both types of skills.

The model's three key features serve to strengthen and formalize the relationship among course content, communication, and library research and improve the relevance of the business course work for students:

- Recitation sessions allow students to interact with course content and information resources while completing their assignments in the presence of experts.

- Collaboration combines the talents and expertise of instructors in business, research, and composition.

- Reframing assignments improves their relevance and context and gives students "real world" 'situations to which they can apply their new skills.

One area for future research is the applicability, of our integrated instructional method to nonbusiness courses. A primary motivation for the model's development was to help students conduct library research and communicate findings using the language of business. The model may not, however, have as much relevance for students preparing for professions where writing and communication of information changes little from the traditional classroom to the workplace. The model does seem to hold promise for other professional and technical education programs in which traditional composition and presentation methods are at odds with those used in the workplace.

The experience of working with this instructional model and the results of these activities have been both exciting and rewarding. The key features of the model hold promise in improving student learning outcomes, particularly in the context of teaching students to communicate business information. As suggested, these key features may be adapted for use at other institutions. We hope that librarians will look for innovative ways to collaborate with subject and composition faculty, to create workshop contexts for student interaction with 
experts, and to reframe assignments in ways that offer students the opportunity, to apply course learning to situations they would encounter in their work lives.

\section{References}

Bogardi, P., Knudsen, A., \& Schildt, C. (200 I). Swedosclerosis or pseudosclerosis? Issues in Political Economy, 10 (Available: http://www.elon.edu/ipe/sweden.pdf. Accessed May 5, 2002).

Business-Higher Education FOnlm (1997).. Spanning the chasm: Corporate and academic cooperation to improve work-force preparation. Washington, DC: Author.

Christensen, P. (1994). Using English department library liaisons in a term paper clinic: Reviving the scholar/ librarian model.. Research Strategies, 12(4), 196-208.

Cohen, C. (1995). Faculty, liaison: A cooperative venture in bibliographic instruction. Reference Librarian, 51/52, $161-169$.

College of Business Administration, University of Nebraska-Lincoln. Facts about the college. Available: httpi//www.cbaunledu/aboutlfacts.html._._. Accessed May 4, 2002.

Crawford, P. J., \& Barrett, T. P. (1997). The reference librarian and the business professor: A strategic alliance that works. Reference Librarian, 58, 75-85.

Diamond, T., \& McGee, J. E. (1995). Bibliographic instruction for business writing students: Implementation of a conceptual framework at Louisiana State University; $R Q, 34(3), 340-360$.

Fennick, R., et al. (1993). Solving problems in twenty-first century academic and workplace writing. English Journal, 82(3), 46-53.

Gavin, C. (1994). Guiding students along the information highway: Librarians collaborating with composition instructors. Journal of Teaching Writing, 13(1-2),225-235.

Hanson, J. (1985). Teaching information sources in business studies: An application of the theories of 1. Bruner and R.M. Gagne. Journal of Librarianship, 17(3), 185-199.

Henninger, E. A., \& Hurlbert, 1. M. (1996). Critical thinking and information across the undergraduate business curriculum. Journal of Business and Finance Librarianship, 2( I), 29-40.

Hudspeth, D. (1992). Just-in-time education. Educational Technology, 32(6), 7-II. ..

Huerta, D., \& McMillan, V. E. (2000). Collaborative instruction by writing and library faculty: A two-tiered approach to the teaching of scientific writing. Issues in Science \& Technology, Librarianship, 28 (Available: http://wwwistlorg/istl/OO-fall/articlel_html__. Accessed. May I, 2002).

Huett, B., Sims, A., \& Villalon, V. (1997). Bibliographic instruction for business classes: How to avoid information overload. Reference Librarian, 58, 87-99.

Hurlbert, J. M., \& Weida, R. A. (1991). Developing a BI project for mathematics research in the small college library. Research Strategies, 9(4), 189-194.

Isbell, D., \& Broaddus, D. (1995). Teaching, writing and research as inseparable: A faculty-librarian teaching team. RSR: Reference Services Review, 23(4), 51-62.

Jacobson, F. (1987). Issues in the implementation of an information-gathering competency requirement in business. Research Strategies, 5(1),18-28.

Judd, V. C., \& Tims, B. J. (1996). Integrating bibliographic instruction into a marketing curriculum: A hands-on workshop approach using team-teaching. RSR: Reference Services Review, 24( I), 21 - 30.

Kendrick, J. W. (1985). BI for business students. College and Research Libraries News, 96(4), 482 -486.

Lubans, 1. (1999). When students hit the surf: What kids really do on the Internet. And what they want from librarians.. School Librmy Journal, 45(9), 144-147.

Mai, B., \& Nixon, J. (1997). Purdue University's Management and Economics Library educates all undergraduate students. indiana Libraries, 16(1),38-42.

Mellon, C、 (1984). Process not product in course-integrated instruction: A generic model of library research. College and Research Libraries, 45(6), 471-478. 
Morrison, J. L., Kim, H., \& Kidd, C. T. (1998). Student preferences for cybersearch strategies: Impact on critical evaluation of sources. Journal of Education for Business, 75(5), 264-268.

Moylan, M. E. (1997). Bibliographic instruction and source materials for undergraduate students in international business. Journal of Business \& Finance Librarianship, 2(4), 21-35.

O'Keefe, J. (1998). One step at a time: A framework for introducing business students to basic sources of company and industry data. Research Strategies, 16( I), 71- 77.

Roebuck, D. B. (1998). Using team learning in business and organizational communication classes. Business Communication Quarterly, 61(3), 35-49.

Schaible, R., \& Robinson, B. D. (1995). Collaborating teachers as models for students. Journal on Excellence in College Teaching, 6(1), 9-16.

Sivan, A., Leung, R., Woon, C., \& Kember, D. (2000). An implementation of active learning and its effect on the quality of student learning. Innovations in Education and Training International, 37(4), 381-389.

Ternberg, M. (1985). BI for accounting students. College and Research Libraries News, 6, $293-294$. 